\title{
National Reference Measurement: What Can It Tell Us about Staffing? Marjorie E. Murfin
}

\begin{abstract}
A study was done with the overall goal of developing a method for determining the adequacy of reference desk staffing. Reference transaction totals, person hours, percent of professional hours, and turnstile count for 1979 were obtained from seventy-one academic libraries of all sizes. A correlation study was done and it was found that turnstile count and person hours accounted for .73 percent of all variation. Norms are given for libraries of four sizes in units of measurement for (1) success in reaching target population, (2) potential patron load, (3) hourly work load, and (4) hourly capacity.
\end{abstract}

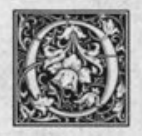

ne of the major problems in the measurement and evaluation of reference service is lack of sufficient knowledge concerning staffing levels. The persistent need for more knowledge in this area is expressed in an article by William Jones entitled "How Many Reference Librarians Are Enough?"'1 This plaintive and as yet unanswered refrain lingers uneasily in the background during many staff and administrative conferences. The many articles which have been written in this area bear witness to the concern of the profession with this issue. ${ }^{2}$

Slater's survey of public service in special libraries in Great Britain underscores this problem when she notes that only 14 percent of public service staffs surveyed approved of the current ways of assessing staffing levels. Some of the negative methods mentioned were educated guesswork, spot decisions, unilateral decisions by administrators or outside experts with unit head or personnel not consulted, decisions for financial considerations only or with a complete lack of any system or rationale at all. ${ }^{3}$

What kind of data do we need to aid us in making difficult staffing decisions? Reference departments have long been accustomed to recording reference transactions on the local level and have gained some helpful information. However, many questions remain unanswered and more information is needed. Particularly pressing now to reference administrators and staff are questions such as the following:

- How great is the demand for reference service above and beyond what we are able to provide at present?

- If we furnished more hours would we receive more questions?

- How adequate is our staff to meet demand in terms of our particular group of users?

- How adequate is our staffing in terms of individual work load?

- How can we obtain the data we need to answer these questions?

Some methods are needed by which comparisons between libraries can be made. Reference staff and administrators need units of measurement which will relate staffing to users and reference transactions in meaningful ways. Without accepted units of measurement, data for different libraries cannot be compared.

Marjorie E. Murfin is reference librarian and associate professor, Ohio State University, Columbus. 
Support for units and ratios of public service measurement utilizing users, staff, and transactions appears to be increasing and can be noted in a number of sources. Measurements such as these are in use in Great Britain as tools for evaluation of staffing adequacy and are in common use for evaluation of staffing in other British service occupations as well. ${ }^{4}$ In Australian academic libraries staff hours have been shown to be correlated with volume of public service activities. ${ }^{5}$ Also, in the United States, a study by Regazzi and Hersberger found that the number of users in the reference area was correlated with the number of reference questions at the .74 level. ${ }^{6}$ In addition, such ratios have been officially recommended for use by public libraries in this country, as one means of measuring and evaluating public service activities.

The need for national measurement of public services is strongly supported in Slater's work. She notes that units of measurement and norms are necessary for forecasting and planning at the organizational and national levels. Norms are also helpful as basic information necessary to set desirable or satisfactory levels which might serve as staffing guidelines. They permit us to check existing and optimum staffing levels at repeated intervals. ${ }^{8}$ Other possible uses of such measurements are pinpointing of problem areas, supplying objective documentation to resolve problems, providing a basis for comparison to assess the effects of change, supporting needed improvements in inadequate service, or continued maintenance of good service. ${ }^{9}$

In 1973, reference question totals were first recorded on the national level in the Higher Education General Information Survey (HEGIS). However, those data have not yet been utilized to relate staffing level, users, and reference transactions in a way to be of benefit to reference service. To attempt to do this has been the overall goal of this study.

More specifically, one goal has been to learn which factors are associated with a high volume of reference transactions and which with a low volume of reference transactions in academic libraries. In 1979, the national college and university refer- ence transaction totals from the HEGIS survey for 1977 were studied by Aluri and Kaske and no correlations with any library performance measures were found. ${ }^{10}$ Two other studies, however, indicated that the volume of reference transactions in a particular library appeared to be influenced to a substantial extent by (1) the number of persons in the library, ${ }^{11}$ and (2) the number of individual reference-person hours furnished. Fully .80 of variation in the second study could be accounted for by these two factors. ${ }^{12}$

The author wished to learn if the national reference transaction data had failed to correlate with available library performance measures in the Aluri-Kaske study because (1) the transaction totals were faulty in that they did not represent comparable units, or (2) the transaction totals were faulty for some other reason which we cannot determine.

Further goals were:

1. to develop units of measurement which would represent the relationship between users, staff hours, and transactions.

2. to illustrate how these measurements might be used on a national level for determining the norms of different sized academic libraries. A given library might then determine whether it falls above or below the norms and evaluate the significance of this in light of its own library structure and goals.

\section{METHOD}

In order to determine whether the national reference transaction data were faulty because they did not represent comparable units, it was decided to limit the data to main library reference departments. It was realized, of course, that there would still be, even with this limitation, a great variety of organizational arrangements and philosophies with regard to reference service in main libraries. Nevertheless, if a relationship was found, in spite of these many internal differences, it would indicate that the data were worthy of further careful research.

Brief questionnaires were then sent out to a stratified sample of small, medium, and large academic libraries with collec- 
tion sizes varying from 121,000 to $9,000,000$ volumes. Asked for were:

1. 1979 HEGIS reference transaction totals

2. turnstile count for the main library for the same week

3 . individual reference-person hours furnished that week

4. the number of these hours which were nonprofessional

5 . hours the reference department was open for service

As noted above, this information was requested for the main library only. Seventy-one complete sets of data were obtained; thirty-four for libraries with turnstile counts over 20,000 (in one week) and thirty-seven for libraries with turnstile counts less than 20,000 (in one week).

The following 1979 data were then collected for each library system from the American Library Directory and other sources.

- Volumes in collection

- Number of serial subscriptions

- Number of professional staff

- Total number of staff

- Support-public or private

- Type college-community college, fouryear programs without graduate, fouryear programs with graduate, university

The above library performance measures, of course, represented the entire library system, while the reference data obtained by the questionnaire represented the main library only. However, if a correlation was found, in spite of these differences in library systems, it would again indicate that further research would be worthwhile. The data collected by questionnaires were then correlated with the library performance measures listed above. The results of these correlations are reported in the following section "Correlation Study."

Units of measurement were also developed from these data to represent relationships between staffing, hours, users, and transactions. Using these measures, it was possible to develop norms or ranges for academic libraries in five groups according to size, as measured by turnstile count, and these are presented in the "Units of Measurement" section.

\section{CORRELATION STUDY: RESULTS AND ANALYSIS*}

The national HEGIS reference transactions totals appear to have some reliability and validity. Using curvilinear regression analysis, the following correlations were found:

Reference transaction totals and turnstile count

Reference transaction totals and individual hours

Reference transaction totals and volumes in collection

Reference transaction totals and enrollment

Reference transaction totals and number of professional staff

Reference transaction totals and size (grouped by turnstile count in 3 groups).74

Multiple correlation

Turnstile count

Individual hours

Hours of service

Number volumes in collection

Percent individual hours by professional librarians

State or private

Type of college (four-year with grad, fouryear with no grad, university)

The formula for the above multiple correlation can be found in appendix A.

As a result of the above correlations, it was concluded that meaningful comparison of the national HEGIS reference totals might be possible if these totals were accompanied by an indication of which units and/or libraries are represented by the totals. In addition to indicating the unit and/or library, as was done in this study, any other separate reference service points in a main library, for example, should also be indicated, such as documents, microform, undergraduate library, etc. If this is done, libraries and researchers can compare like units in a meaningful way.

The most important factor in explaining

\footnotetext{
*Thanks is given for the kind assistance of Fred Rutland, Senior Statistician, Instruction and Research Computer Center, Ohio State University.
} 
the variation in reference transactions appeared to be turnstile count. When this important factor was equated by comparing libraries with similar turnstile counts, in the great majority of cases the library with the most person hours had the most questions. Together, turnstile count and person hours accounted for .73 of the variation in numbers of reference questions.

It is the opinion of the author, based on the previous and present studies, that turnstile count could become one of the best predictors of public service activities available to academic libraries. This need for measurement of actual users is supported by Slater, and the rationale for this is discussed in more detail in her paper. ${ }^{13}$

It was felt that a higher correlation between number of reference questions and turnstile count would have been obtained had there been more accuracy in recording and interpreting the turnstile count in some cases. Unfortunately, the usefulness of turnstile count as a predictor of public services does not seem to be recognized to any extent at the local level. In some academic libraries it is recorded carelessly or ignored. On the national level the inclusion of turnstble count in the HEGIS survey has been considered, but no further progress has been made.

The importance of person hours as a public service predictor is documented in Strayner's work, where he found the highest correlation of all performance measures obtained was for individual staff hours. ${ }^{14}$ Individual staff person hour data should not ordinarily be difficult to obtain since it involves merely a count of person hours taken from the weekly schedule. If person hours for the sample week and turnstile count are also included, then understanding can be gained as to the probable reasons that one library has more reference questions than another, and staffing inadequacies can be detected.

In regard to estimating the probable number of reference transactions a particular library will have during the sample week, a stepwise regression indicated that person hours and turnstile count would account for .73 of the variation.

This formula, which requires transposition to logarithms, is given as formula II in the appendix.
It was also found, to the author's surprise, that another two-factor model was almost equally effective in estimating number of reference transactions. This model accounted for variation at the .72 level and consisted of number of volumes and enrollment. This formula is given in the appendix as formula III.

This formula might be useful in estimating the probable number of questions a library might be expected to have during the sample week. One advantage of this formula is that the data are readily available to all academic libraries. It is not as useful in interpreting reference transaction data and detecting staffing inadequacies as the formula based on users and hours, or the formula based on users and hours plus other factors. Correlations such as the above, however, still leave much variation unexplained and this must always be borne in mind when interpreting results.

\section{UNITS OF \\ MEASUREMENT AND NORMS: RESULTS AND ANALYSIS}

It must be emphasized that these ranges are based on a small sample and, further, do not make allowance for the precise configuration of reference service within a particular library. They do, however, provide a rough yardstick for main library services and illustrate the way such norms or ranges could be useful if they were collected on a national level and precisely marked according to type and service point.

These ranges are presented in this article only as illustrations of what might be done on a national level and are not refined precisely to represent different reference configurations in main libraries. Therefore, they should not be used as a basis for any kind of final judgment, but only for the purpose of alerting a library when it falls outside the range for libraries of its size and type. This divergence might be only because internal reference arrangements or usage of the library are different from other main libraries of its size and type. Therefore, the ranges presented here should be carefully interpreted by each individual library in the light of its internal structure. 
If these measurements were collected on a national level and carefully labelled in regard to the reference configuration of the library system, libraries with similar internal reference structures could be compared and interpretations could then be made with less difficulty. However, even then, there should be no uniform significance in a library's being above or below the norms or ranges. The final judgment as to the significance of this must be interpreted in the light of an individual library's mission and goals.

Units of measurement and ratios discussed here will be given two ways in most of the following tables: (1) based on turnstile count, and (2) on enrollment.

Turnstile count groups were a slightly better predictor than enrollment groups overall, but enrollment is much more easily obtainable and perhaps less subject to errors of reporting and recording and is closely related to the mission of the library's reference service. Overall, turnstile and enrollment were correlated at .70 .

Turnstile count and enrollment were less closely related for libraries up to $29,999(0-29,999$ turnstile or enrollment), but there is, however, a closer correspondence between enrollment and turnstile count for libraries 30,000 turnstile count and above. Turnstile count is probably to be preferred because, in some cases, the number in the library, for one reason or another, is strikingly out of proportion to the enrollment, as in example A. (When particular examples are given throughout this paper all numbers have been altered to prevent identification of any one library.) However, the correlation with enrollment overall was sufficiently strong to be very useful.

\section{Success in Reaching}

the Target Group of Users

This measure enables a reference department to determine to what extent its reference service is reaching those in the library as compared to other institutions of the same type and size. It consists of the percentage of the turnstile count who asked reference questions during the sample week.

Figure 1 gives the approximate percentage of persons involved in reference transactions as compared to: (1) those actually in the library (or turnstile count for the sample week), and (2) students enrolled. Academic libraries may obtain this percentage by dividing their total number of reference transactions for the HEGIS week by the number of users in the library during the sample week or by enrollment. These percentages may then be compared with the library's goals and also with the levels achieved by other libraries of the same size.

\section{Demand}

Perhaps the most greatly desired measurement by both reference personnel and administrators is some unit of measurement for demand.

By way of background, reference departments have long been accustomed to using a count of reference questions as a measure of demand. By comparing reference question totals over a period of time, fluctuations can be noted. Since individual reference staffing patterns are usually very consistent over time, any fluctuation in number of questions can usually be attributed to an increase or decrease in demand, rather than to the furnishing of significantly more or fewer staffing hours.

When national reference totals were first taken in 1973, the possibility existed that totals of reference questions might be able to be used on a national level to compare the amount of demand for reference service in various academic libraries. However, this study indicated that when reference question totals were compared between different libraries, differences in totals could not easily be attributed only to

$\begin{array}{cc}\text { Library } & \text { Reference } \\ \text { Transactions } \\ \text { C } & 2,740 \\ \text { D } & 941\end{array}$




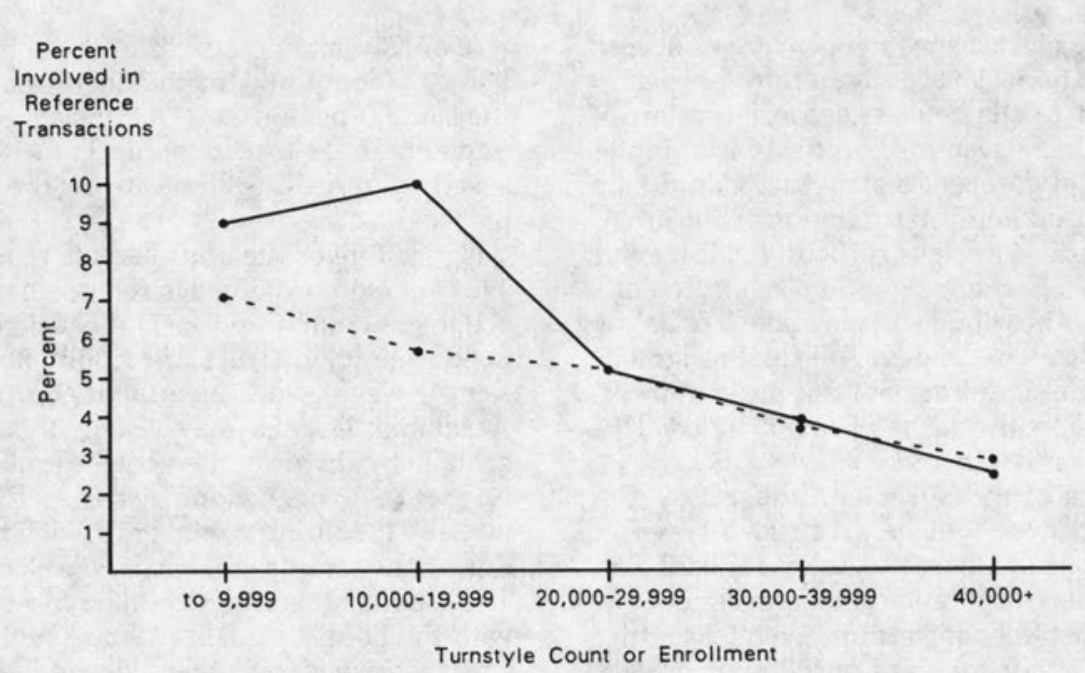

\begin{tabular}{|c|c|c|c|}
\hline & $\begin{array}{c}\text { Perce } \\
\text { in }\end{array}$ & $\begin{array}{l}\text { rollment Involved } \\
\text { e Transactions }\end{array}$ & $\begin{array}{l}\text { Percent of } \\
\text { Users in } \\
\text { Library } \\
\text { Involved in } \\
\text { Reference } \\
\text { Transactions }\end{array}$ \\
\hline & & $(-)$ & $(---)$ \\
\hline ze 1 & to 9,999 & $9.0 \%$ & $7.2 \%$ \\
\hline e 2 & $10,000-19,999$ & $10.0 \%$ & $5.7 \%$ \\
\hline 3 & $20,000-29,999$ & $5.2 \%$ & $5.2 \%$ \\
\hline e 4 & $30,000-39,000$ & $3.8 \%$ & $3.7 \%$ \\
\hline & $40,000+$ & $2.5 \%$ & $2.8 \%$ \\
\hline
\end{tabular}

FIGURE 1

Success in Reaching Users

demand, since staffing levels varied widely. For example, in libraries with 20,000-29,999 turnstile counts, person hours furnished varied from 67 to 302 for the sample week.

If two libraries have approximately the same number of users in the library during the sample HEGIS week, the library which furnishes more person hours will, in the great majority of cases, have more questions.

Example B illustrates the importance of person hours as it compares two libraries similar in turnstile count and enrollment.

On the basis of these examples we can see that number of reference transactions cannot be equated with demand because the number of transactions is highly dependent on the number of hours furnished. Therefore, we can only look at reference transaction totals as demand demonstrated and met with present staffing limitations.

The demand as met is shown in terms of ratios in table 1. (Demand as met and success in reaching users are two ways of looking at the same data. The first is expressed as a percentage and the second as a ratio.) As can be seen, as the number of users in the library increases, fewer and fewer of those users will be involved in a reference transaction. This will be discussed further in a later section.

\section{Potential Demand}

Potential demand is more difficult to measure in that it consists of all those who actually asked questions during the sample week plus those who intended to consult reference but did not because reference personnel were too busy. A queueing study, or "nuisance factor" 


$\begin{array}{ccccc}\text { Library } & \text { Reference } & \text { Tours } & \text { Enrollment } & \text { Turnstile } \\ \text { A } & \text { Transactions } & \text { Hours } & 12,476 & 20,000 \\ \text { B } & 1,200 & 119 & 13,647 & 20,974\end{array}$

EXAMPLE B

study, ${ }^{15}$ may be done, but we may also approach the problem in another way.

This concept of potential demand is based on the evidence of this and the author's previous study which indicates that as the number of users in the library grows larger, fewer of those in the library will ask reference questions.

The hypothesis that, as the library grows larger and more complex, users have less need for reference service does not appear to be a tenable one. The following hypothesis is offered instead.

Due to (1) the number of people in the large library and (2) the fact that reference hours do not increase in proportion to increases in turnstile count, there is more competition for each available reference hour in the large library. Therefore, many people are discouraged from asking reference questions.

\section{Adequacy of Staffing in Terms of Hours and Users}

A measure of the potential adequacy of staffing has been termed "potential patron load." This is obtained by dividing the number of users in the library (or the number of students enrolled) by the number of person hours furnished. Norms are shown graphically in figure 2 by number of users in the library and by enrollment.

Potential patron load appears to be closely related to the proportion of those in the library who will be involved in refer- ence transactions. The graphs in figures 1 and 2 show that as potential patron load increases, percentage of users involved in reference transactions decreases.

In light of what we know about the importance of staffing hours in determining the total number of questions, it would appear that the decrease in the proportion of those served is due to lack of sufficient individual staffing hours rather than to lessened demand. As the potential patron load increases, reference services appear to lose accessibility. For this reason, comparison of potential patron load factors might be helpful in determining why a library's reference service is reaching a lower proportion of users than is desired. We can also note that potential patron loads over 300 appear to have a strong adverse effect on percent of patrons in the library who will receive (or be able to obtain) reference service.

\section{Work load}

One of the original purposes of reference measurement on the national level had been to compare reference work loads. ${ }^{16}$ The most graphic and useful measurement for this purpose appeared to be not total number of transactions, but number of transactions per staff-person hour. This can be obtained by dividing the number of transactions in one week by the number of reference-person hours furnished. Table 2 shows the norms or ranges

TABLE 1

DEMANDS AS MET WITH PRESENT STAFFING LEVELS (BY TURNSTILE COUNT AND ENROLLMENT FOR SAMPLE WEEK)

\begin{tabular}{|c|c|c|c|c|c|}
\hline & $\begin{array}{l}\text { Turnstile } \\
\text { Count or } \\
\text { Enrollment } \\
\text { (To 9,999) }\end{array}$ & $\begin{array}{c}\text { Turnstile } \\
\text { Count or } \\
\text { Enrollment } \\
(10,000-19,999) \\
\end{array}$ & $\begin{array}{c}\text { Turnstile } \\
\text { Count or } \\
\text { Enrollment } \\
(20,000-29,999) \\
\end{array}$ & $\begin{array}{c}\text { Turnstile } \\
\text { Count or } \\
\text { Enrollment } \\
(30,000-39,999) \\
\end{array}$ & $\begin{array}{l}\text { Turnstile } \\
\text { Count or } \\
\text { Enrollment } \\
(40,000+)\end{array}$ \\
\hline $\begin{array}{l}\text { One in } \\
\text { involved in reference } \\
\text { transactions } \\
\text { One in enrolled will be }\end{array}$ & 1 in 7.44 & 1 in 15.77 & 1 in 17.5 & 1 in 30.28 & 1 in 40 \\
\hline $\begin{array}{l}\text { One in } \\
\text { be involved in refer- } \\
\text { ence transactions }\end{array}$ & 1 in 11.0 & 1 in 10.0 & 1 in 19.0 & 1 in 26.0 & 1 in 39 \\
\hline
\end{tabular}




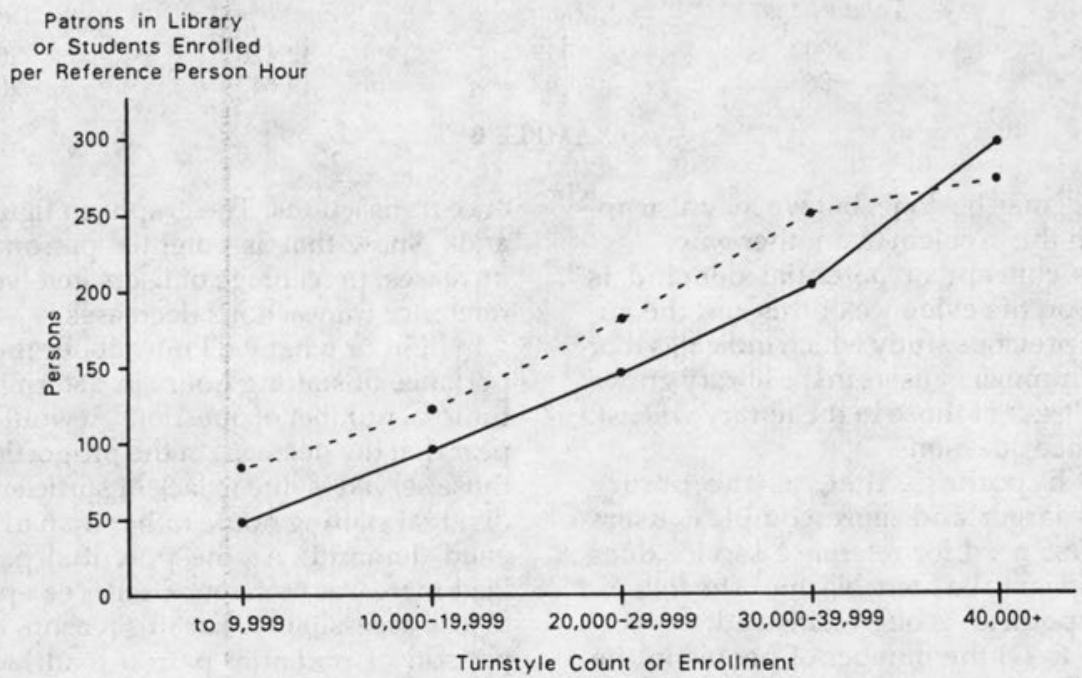

$\begin{array}{llcr} & & \begin{array}{c}\text { Students Enrolled per } \\ \text { Reference Person Hour }\end{array} & \begin{array}{r}\text { Patrons in } \\ \text { per Perso }\end{array} \\ \text { Size 1 to } 9,999 & (-) & 82 \\ \text { Size 2 } & 10,000-19,999 & 49 & 122 \\ \text { Size 3 } & 20,000-29,999 & 142 & 178 \\ \text { Size 4 } & 30,000-39,000 & 204 & 248 \\ \text { Size 5 } & 40,000+ & 297 & 273\end{array}$

FIGURE 2

Potential Patron Load

found in this study for work load per hour for libraries of different sizes.

It can be seen that work load increases up until turnstile count of 30,000 . The decrease at this time is probably due, in part, to the demand being spread among more service points. Libraries can compare their individual work loads with their own goals and also with other libraries of their own size.

\section{Actual Capacity of}

\section{Reference Services Per Hour}

Capacity is defined here as the maximum number of reference transactions that are handled by the desk staff on duty per hour service is available. This measurement does not apply to libraries with up to 9,999 turnstile count since the average hourly work load (reference questions per hour) in these libraries in this study was less than that which could be handled by one person. The measurement of ca- pacity is intended to determine how many patrons can be served per hour, above and beyond the capacity of one reference staff person. Actual capacities found in this study for libraries of different sizes are shown in table 3.

Central reference services appear to reach maximum capacity in libraries with turnstile counts of 30,000 and above, where some sixteen transactions per hour are handled on the average. This, of course, is the average for all hours that service is available, including the slowest hours. Therefore, during busiest hours twice as many transactions might be handled. From this point on, capacity does not appear to increase in the central reference department.

\section{INTERPRETATION OF UNITS OF MEASUREMENT}

Examples are given here of how four of these measures-success in reaching us- 
TABLE 2

WORK LOAD (NUMBER OF REFERENCE TRANSACTIONS PER PERSON PER HOUR)

\begin{tabular}{|c|c|c|c|c|c|}
\hline $\begin{array}{l}\text { Reference Transactions } \\
\text { Per Person Hour }\end{array}$ & $\begin{array}{c}\text { Turnstile } \\
\text { Count or } \\
\text { Enrollment } \\
\text { (To 9,999) }\end{array}$ & $\begin{array}{c}\text { Turnstile } \\
\text { Count or } \\
\text { Enrollment } \\
(10,000-19,999)\end{array}$ & $\begin{array}{c}\text { Turnstile } \\
\text { Count or } \\
\text { Enrollment } \\
(20,000-29,999)\end{array}$ & $\begin{array}{c}\text { Turnstile } \\
\text { Count or } \\
\text { Enrollment } \\
(30,000-39,999)\end{array}$ & $\begin{array}{c}\text { Turnstile } \\
\text { Count or } \\
\text { Enrollment } \\
(40,000+)\end{array}$ \\
\hline $\begin{array}{l}\text { By turnstile count groups } \\
\text { By enrollment groups }\end{array}$ & $\begin{array}{l}3.42 \\
4.45\end{array}$ & $\begin{array}{l}6.27 \\
9.54\end{array}$ & $\begin{array}{l}9.29 \\
7.41\end{array}$ & $\begin{array}{l}7.98 \\
7.50\end{array}$ & $\begin{array}{l}7.43 \\
7.53\end{array}$ \\
\hline
\end{tabular}

TABLE 3

ACTUAL CAPACITY

\begin{tabular}{|c|c|c|c|c|c|}
\hline & $\begin{array}{l}\text { Turnstile } \\
\text { Count or } \\
\text { Enrollment } \\
\text { (To 9,999) } \\
\end{array}$ & $\begin{array}{c}\text { Turnstile } \\
\text { Count or } \\
\text { Enrollment } \\
(10,000-19,999) \\
\end{array}$ & $\begin{array}{c}\text { Turnstile } \\
\text { Count or } \\
\text { Enrollment } \\
(20,000-29,999) \\
\end{array}$ & $\begin{array}{c}\text { Turnstile } \\
\text { Count or } \\
\text { Enrollment } \\
(30,000-39,999) \\
\end{array}$ & $\begin{array}{c}\text { Turnstile } \\
\text { Count or } \\
\text { Enrollment } \\
(40,000+) \\
\end{array}$ \\
\hline $\begin{array}{l}\text { Actual demonstrated ca- } \\
\text { pacity (RT per hour ser- } \\
\text { vice available) }\end{array}$ & 4.06 & 11.17 & 15.32 & 16.19 & 14.98 \\
\hline
\end{tabular}

ers, potential patron load, work load, and capacity - can be used to evaluate staffing levels.

We might first take several libraries whose success in reaching their users is considerably less than average for their size group. Data presented are altered to protect identity of the libraries involved.

In table 4, example 1 , it appears that $\mathrm{Li}$ brary A's below-average success in reaching its users is due to severe understaffing and lack of capacity rather than to lack of demand.

Another case of a library with less-thanaverage success in reaching its target group can be seen in example 2 . This library's lower success cannot be explained by any of the above factors and it does not appear to be clearly understaffed as does Library A. Many explanations are possible and only the library concerned can properly interpret this situation. Norms or ranges can merely serve as an alerting device and, in some cases, suggest possible reasons for lower success.

In the case of Libray C, example 3, we see a library clearly understaffed, yet successful in reaching its users according to the norms for its size group. We can see that this is done at tile cost of carrying a heavier individual work load and, thus, probably giving each patron less time than is the case with other libraries of its size.

Finally, another example shows how these norms might be used. A problem of inaccessibility in a reference service has been previously described in the literature. Using data from that article and enrollment norms from this study we see the following:

Norms for Li-

$$
\begin{array}{cc}
\text { Enrollment } & \text { Mean Number } \\
\text { Per Person } & \text { Person Hours } \\
\text { Hour } & \text { Furnished }
\end{array}
$$

braries of Size 2

\begin{tabular}{crr} 
Enrollment & 81 & 146 \\
\hline \hline Library X & 269 & 67
\end{tabular}

Library $X$ is clearly staffed at less than half that of comparable libraries and the resulting problem of inaccessibility is clearly understandable.

\section{PROFESSIONAL AND NONPROFESSIONAL REFERENCE STAFF HOURS}

If libraries were matched for potential patron load, collection size, and turnstile count, it did appear that there would be a slightly higher rate of reference transactions where most of the reference hours were professional and a slightly lower rate when most were nonprofessional. This is in line with the findings of a previous study. $^{17}$

Concerning professional and nonprofessional staff hours, there did not appear to be a difference in the percentage of professional hours furnished, according to the size of the library (by turnstile count). 
TABLE 4

EXAMPLES

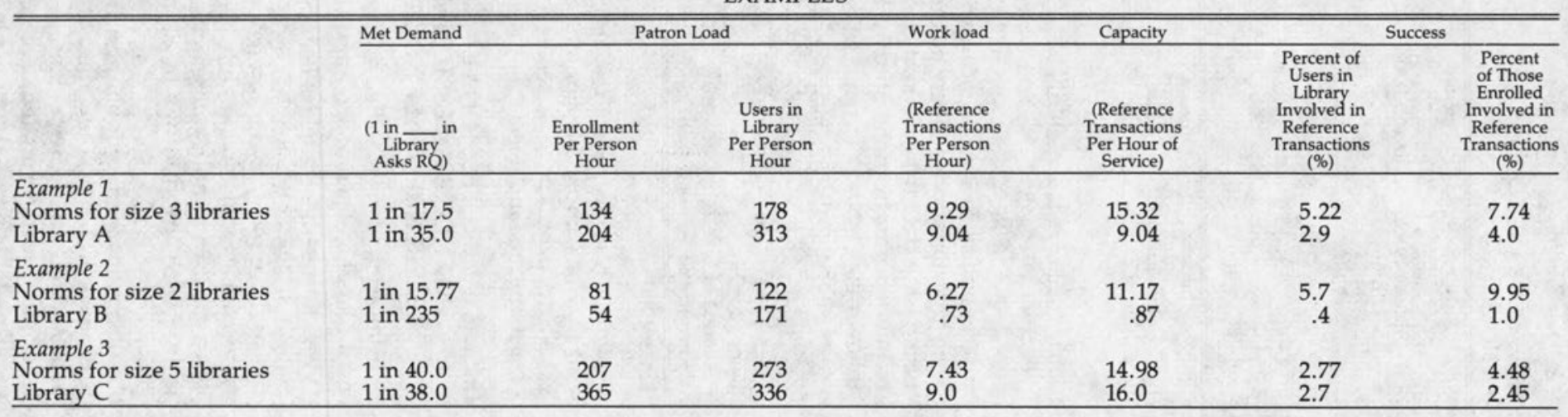

TABLE 6

STATE AND PRIVATE INSTITUTIONS PERCENTAGE OF PROFESSIONAL-PERSON HOURS

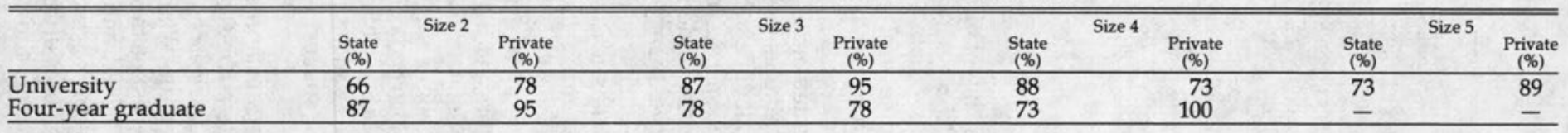

TABLE 7

POTENTIAL PATRON LOAD IN PUBLIC AND PRIVATE INSTITUTIONS

\begin{tabular}{|c|c|c|c|c|c|c|c|c|c|c|}
\hline & Size 1 & Size 2 & $\begin{array}{l}\text { Public University } \\
\text { Size } 3\end{array}$ & Size 4 & Size 5 & Size 1 & Size 2 & $\begin{array}{c}\text { Private University } \\
\text { Size } 3\end{array}$ & Size 4 & Size 5 \\
\hline Users in library per person hour & - & 90 & 169 & 248 & 262 & 69 & 163 & 214 & 247 & 363 \\
\hline
\end{tabular}


TABLE 5

PERCENTAGE OF PROFESSIONAL-PERSON HOURS FURNISHED AND PATRON LOAD

\begin{tabular}{|c|c|c|c|c|c|c|}
\hline & $0-30 \%$ & $30.50 \%$ & Percentage of Professio & erson Hours & $80-00 \%$ & $00-100 \%$ \\
\hline Average patron load & 114 & 117 & 194 & 206 & 219 & 203 \\
\hline
\end{tabular}

There did appear to be a clear relationship between patron load and percentage of professional hours. For libraries of 20,000 turnstile count and above, those reference staffs with a higher percentage of professionals also had higher potential patron loads (see table 5). This is logical in that professional reference librarians are expensive, fewer can be afforded, and thus patron loads are higher. It appears that reference departments make a choice between higher-paid professional help and fewer individual work hours or lower-paid nonprofessional help and more work hours.

\section{Collection Size}

Another finding indicated that as the size of the collection increased, the percentage of professional hours decreased. It was also found in regard to collection size, when libraries were matched in regard to patron load, those with the larger collections appeared to have a higher rate of reference transactions.

\section{Public and Private Institutions}

Private universities and private fouryear institutions with graduate programs tended to have a higher percentage of professional hours at almost all levels (see table 6).

The average number of reference transactions was greater for public institutions than for private. However, when patron load, collection size, and percent of professional hours were matched, there did not appear to be a difference between public and private institutions in regard to rate of reference transactions.

\section{Public Matched Groups Private \\ Universities \\ Universities}

1 in 31.2 in library in- 1 in 31.7 in library involved in a reference volved in a reference transaction
Instead, the lower average number of reference transactions in private institutions appears to be due primarily to lesser levels of staffing with higher potential patron loads (see table 7).

\section{SUMMARY AND CONCLUSIONS}

Regarding the national collection of $\mathrm{HE}-$ GIS reference statistics, it appears that:

1. In order for the national HEGIS data to be meaningfully interpreted, reference transaction totals should be accompanied by an indication of which units within the library and/or libraries are represented by the totals.

2. If this is done, it appears that the national HEGIS reference transaction totals can be meaningfully interpreted and do correlate with expected performance measures such as enrollment and collection size.

3. If HEGIS reference totals are accompanied by reference person hour totals and library turnstile count for the sample week, a substantial part of the variation in reference questions can be accounted for.

4. On the basis of this, and with further research, useful norms can be established in regard to users, hours, and reference transactions.

5. Norms should be in terms of ratios, as is suggested in the new Public Library Guidelines.

6. These norms should not be accepted as standards, but could serve as measuring sticks for libraries wishing to judge the adequacy of their staffing in relation to other libraries of their size and type.

7. Possible measurements are ratios for potential patron load, work load, success in reaching users, and capacity per hour.

We are very close to having the tools we need to evaluate reference and public service staffing levels nationally. The two additional measures needed-hours and users-are both easily obtainable, the first 
taken directly from the weekly schedule in a few minutes time and the second from a simple reading of the turnstile count for the sample week. If we can only travel that last mile and obtain (1) indications of what libraries and/or units are represented by reference transaction totals, (2) individual reference person hours of desk service, and (3) turnstile count, we may have national measurement of staffing level in terms of meaningful ratios within our grasp. This is an opportunity which should not be let slip away.

Because library reference services are highly individual in their organization and arrangement, users, and types of questions, each library must take ultimate responsibility for judging the adequacy of its staffing. It is only hoped that norms such as these might be one tool of many to help strengthen and maintain staffing to meet our patron's needs.

\section{REFERENCES}

1. William H. Jones, "How Many Reference Librarians are Enough?" RQ 14:16-18 (Fall 1974).

2. Stephen P. Harter and Mary Alice Fields, "Circulation, Reference, and the Evaluation of Public Library Services," RQ 18:147-52 (Winter 1978); Candace Morgan, "The Reference Librarian's Need for Measures of Reference," $R Q$ 14:11-12 (Fall 1974); John J. Regazzi and Rodney M. Hersberger, "Queues and Reference Service: Some Implications for Staffing," College and Research Libraries 30:293-98 (July 1978); Paul Kantor, "Quantitative Evaluation of the Reference Process, " $R Q$ 21:43-52 (Fall 1981).

3. Margaret Slater, Ratio of Staff to Users. Implications for Library-Information Work and the Potential for Automation. Aslib Occasional Publication no.24 (London: Aslib, 1981), p.13.

4. Ibid., p.5-9.

5. Richard Strayner, "The Use of Empirical Standards in Assessing Public Library Effectiveness," in Library Effectiveness: A State of the Art, Papers from a 1980 ALA Preconference (Chicago: American Library Assn., 1980), p.351.

6. John J. Regazzi and Rodney M. Hersberger, "Library Use and Reference Service: A Regression Analysis." Paper presented at the ALA Annual Conference, July 18-24, 1976, Chicago, Ill. (ED 129219).

7. "Major New Tool Can Measure Public Library Performance," American Libraries 14:195 (Mar. 1982).

8. Slater, Ratio of Staff to Users, p.1-4.

9. Morgan, "The Reference Librarian's Need for Measures of Reference," p.11-12; Robert Runyon, "The Library Administrator's Need for Measures of Reference," RQ 14:9-11 (Fall 1974).

10. Rao Aluri and Neal Kaske, "Analysis of Library General Information Survey Data on Reference Statistics." Paper presented at a Library Research Roundtable Session, American Library Association Annual Conference, 1980.

11. Regazzi and Hersberger, "Library Use and Reference Service," p.10.

12. Marjorie Murfin and Fred Ruland, "Measurements of Reference Transactions: An In-depth Statistical Study of Demand and Capacity in Twenty-two Libraries over a Two-Year Period, " in Library Effectiveness: A State of the Art. Papers from a 1980 ALA Preconference (Chicago: American Library Assn., 1980), p.207.

13. Slater, Ratio of Staff to Users, p.1-4.

14. Strayner, "The Use of Empirical Standards," p.351.

15. Regazzi and Hersberger, "Queues and Reference Service," p.293-98; Kantor, "Analyzing the Availability of Reference Service," p.132-36.

16. Katherine Emerson, "National Reporting on Reference Transactions, 1976-78," RQ 16:199-207 (Spring 1977), p.206.

17. Murfin and Ruland, "Measurements of Reference Transactions," p.207.

\section{APPENDIX A}

These formulas may be done using a calculator with log and antilog functions.

Formula I

1. Transform each of the following into its log. 

a. turnstile count for sample week
b. number of reference-person hours on desk duty during sample week
c. number of hours reference desk service is available during sample week
d. number of volumes in library's collection
e. enrollment
f. percentage of reference-person hours (b) which are professional

2. Multiply log for turnstile count by

Multiply $\log$ for person hours by

.24617104

Multiply $\log$ for hours reference open by

.36909216

1.30230480

.36787954

Multiply log for volumes in collection by

.11327696

Multiply log for enrollment by

.29829353

3. Add all the products together

4. If private institution, subtract .08548012

If state institution, leave as is

5. If university, leave as is

If four-year graduate institution, add .10647652

If four-year institution without graduate program, add .87598800

6. Take result and subtract 4.06816925

7. Transform answer from log back into regular number

8. Result is predicted number of reference transactions during sample week

\section{Formula II}

1. Transform each of the following into logs

a. turnstile count for sample week

b. number of reference-person hours on desk duty during sample week

2. Multiply $\log$ for turnstile count by .37288818

Multiply log for person hours by .97450198

3. Add these two figures

4. Subtract .76026081

5. Take this answer and transform it from a log back to a regular number

6. Result is the predicted number of reference transactions during the sample week

\section{Formula III}

1. Transform each of the following into logs

a. enrollment

b. number of volumes in library's collection

2. Multiply log for enrollment by .54328357

Multiply $\log$ for volumes by $\quad .14396843$

3. Add these two figures

4. Subtract .20189742

5. Take this answer and transform it from a log back to a regular number 